\title{
Nuevo Directorio, nuevos desafíos
}

\author{
New Directory, new challenges
}

\author{
Carlos García C. ${ }^{1}$ y Luis Fonseca R. ${ }^{2}$
}

Como es tradicional nuestra sociedad ha elegido una nueva directiva para el período 2019-2020. Este proceso se caracterizó por la alta participación, probablemente la mayor de nuestra historia societaria, y por ser la más "política", al presentar cada una de las listas en competencia, un programa de trabajo serio y detallado con propuestas y metas a cumplir. Todo este proceso demostró la madurez alcanzada por la Sociedad de Cirujanos de Chile y que busca lograr los objetivos descritos en nuestros estatutos, en concordancia con la realidad actual. Queremos agradecer el amplio respaldo recibido por la asamblea general al elegirnos como las nuevas autoridades de la sociedad. Evidentemente esperamos estar a la altura de los desafíos propuestos.

El comité ejecutivo lo completan el Dr. Rodrigo Torres-Quevedo como secretario general y la Dra. Marcia Valenzuela como tesorera. Fueron además renovados 8 directores, elegidos durante esta misma asamblea, que representan tanto a los diferentes departamentos o sociedades afiliadas, como a las distintas regiones de nuestro extenso país.

No podemos dejar pasar esta oportunidad para felicitar y agradecer a la directiva saliente encabezada por los Drs. Nicolás Jarufe y Marcelo Barra por todo el trabajo y esfuerzo realizado por el bien de nuestra sociedad. Fueron dos años de gran crecimiento, dando énfasis a aspectos de difusión y educación. Los logros alcanzados son ampliamente conocidos por todos ustedes y merecen nuestro más amplio reconocimiento.

Propusimos a la asamblea de la Sociedad de Cirujanos de Chile un programa que pensamos incluye las necesidades y anhelos de nuestros asociados, los que podemos resumir en cuatro puntos principales: difusión, investigación, formación continua y crecimiento societario.

En los tiempos actuales la comunicación permanente, rápida y efectiva es fundamental para una organización. Desde hace un tiempo, la sociedad decidió contratar un profesional para que estuviese a cargo de esta importante actividad, con la clara intención de mejorar nuestras comunicaciones internas. Este objetivo se logró con creces utilizando las nuevas plataformas digitales y las redes sociales. Pretendemos seguir impulsando y desarrollando esta actividad con una mirada volcada hacia la comunidad, dándonos a conocer quienes somos y cuál es nuestra función. Pretendemos también entregar nuestra opinión, a la comunidad nacional y a todas las instancias que se requiera, con respecto a los temas que nos involucran ya sea técnicos, gremiales $\mathrm{u}$ otros, en los cuales nuestro sentir puede ser un aporte significativo a la discusión.

Uno de los principales objetivos de nuestra sociedad es desarrollar el conocimiento quirúrgico y extenderlo hacia los socios. En nuestros congresos nacionales y jornadas de los distintos departamentos, nos damos cuenta de la gran experiencia y conocimientos que poseen nuestros asociados, lo que no se plasma en investigación, trabajos o publicaciones. Creemos que una manera efectiva de mejorar estos aspectos es impulsar la investigación directamente a través de la Sociedad de Cirujanos de Chile. Debemos invertir en investigación a través de iniciativas que involucren a todos sus asociados y que impulsen de manera relevante el conocimiento quirúrgico. Hemos pensado en desarrollar registros nacionales "on line", desarrollados por distintos departamentos u sociedades adherentes, financiados con aportes de la sociedad o de la empresa privada. También buscaremos los recursos necesarios para financiar otros proyectos de investigación concursables, dando énfasis a estudios cooperativos y multi-institucionales.

La formación continua es un tema de gran relevancia en nuestro quehacer. Si bien la formación de pre y postgrado la realizan las universidades, la formación continua de los cirujanos ya formados está a cargo de las sociedades científicas, a través de diversos mecanismos. Los congresos, jornadas y las publicaciones oficiales son los medios habituales de seguir al corriente del conocimiento quirúrgico. A estos debemos sumar la educación
'Presidente.

'Vice-Presidente.

Correspondencia a: carlosgarciac@gmail.com luisfonsecariquelme@gmail. com 
quirúrgica mediante simulación, de la cual el directorio anterior dio un gran impulso y de los cuales debemos obtener el máximo rendimiento. Además, pretendemos agregar a estos, la formación mediante cursos on line, dirigidos tanto a los profesionales en formación como a todos aquellos que quieran estar al día en los avances de la especialidad. Para estos utilizaremos los medios actuales que cuenta nuestra sociedad, agregando otros, como el desarrollo de páginas web de cada departamento o sociedades afiliadas. Debemos también introducir mecanismos de certificación de nuestros cursos que incluyan el número de horas docentes, de perfeccionamiento y algún mecanismo de evaluación. En necesario recordar que en un futuro seremos sometidos a un proceso de re-acreditación y tener certificación con estas características nos ayudarán enormemente a sortear dichas etapas.

El crecimiento societario fue uno de los principales logros de la directiva anterior. Hubo un aumento significativo de socios, de capítulos regionales, de asistentes a congresos, jornadas y de actividades en general. Pero nos queda mucho. Hay una cantidad significativa de cirujanos que practican esta hermosa especialidad y que no son parte de ella. Las razones son múltiples y sería muy extenso analizarlas, pero pretendemos atraer al máximo posible de especialistas quirúrgicos al seno de nuestra sociedad. Queremos que esta sea atractiva para ellos y para todos. Queremos también profundizar en la participación.
Los congresos y cursos son eventos en que la gran mayoría, sino todos, debemos colaborar, tanto en los procesos organizativos como en el aporte científico y en el desarrollo mismo de estos.

La autoridad sanitaria nos ha solicitado la participación en diversos desafíos propios de esa cartera. Me refiero al problema de resolución de listas de espera (problema aparentemente de difícil solución y no siempre abordados por nosotros, los especialistas) o la nueva ley del cáncer que se encuentra actualmente en etapa pre-legislativa en nuestra congreso. Tenemos opiniones, experiencia y podemos hacer aportes significativos en estos ámbitos.

Deseo recordarles que este año 2019, nuestra sociedad cumple 70 años de vida. El día 30 de marzo de 1949, la sociedad de Cirugía de Chile y la Sociedad de Cirujanos de Hospital decidieron unirse y formar nuestra actual Sociedad de Cirujanos de Chile. Evidentemente que esto debe ser recordado y conmemorado, por ser un hito que nos enorgullece. Realizaremos las actividades societarias correspondientes.

Por último, deseamos invitarlos a participar, a ser parte de nuestra sociedad, activos en su crecimiento, con aportes de ideas, proyectos, comentarios y por qué no, críticas, cuando consideren que algunas de las decisiones tomadas no van en el sentido correcto. Nuestro directorio está abierto a recibir todas ellas por el bien y engrandecimiento de nuestra querida Sociedad de Cirujanos de Chile. 